hayfever remained static (see Figure). There was a low response rate in this survey and the results should be interpreted with some caution but the findings suggest different underlying mechanisms for asthma and other "allergic" conditions.

\section{P98 A QUESTIONNAIRE SURVEY OF PARENT EXPERIENCES AND PERSPECTIVES IN CHILDREN DIAGNOSED WITH INTERSTITIAL LUNG DISEASE (ILD)}

${ }^{1} \mathrm{C}$ Gilbert, ${ }^{2} \mathrm{~A}$ Bush, ${ }^{3} \mathrm{~S}$ Cunningham. 'ChILD Lung Foundation, Wirral, UK; ${ }^{2}$ Royal Brompton and Harefield Trust NHS, London, UK; ${ }^{3}$ Royal Hospital for Sick Children, Edinburgh, UK

\subsection{6/thoraxjn-2014-206260.239}

Background and objectives Paediatric ILD is rare, so even clinicians in large centres will see very few cases. We aimed to report the experience of parents of children diagnosed with ILD in order to inform current clinical practice, and future planning of health care.

Methods Between February 2014 and March 2014, UK based families with children given a diagnosis of ILD completed an anonymous comprehensive web-based survey developed by the chILD Lung Foundation. The survey consisted of mainly closed questions, with some open qualitative questions.

Results Of the 37 families who completed the questionnaire, $70 \%$ of participants reported that they were very happy/happy with the overall management of their child. Diagnoses: unknown $38 \%(\mathrm{n}=14)$, neuroendocrine hyperplasia of infancy $16 \%$ $(\mathrm{n}=6), A B C A 3$ mutations $8 \%(\mathrm{n}=3)$, obliterative bronchiolitis (OB) $24 \%(\mathrm{n}=9)$, follicular bronchiolitis $3 \%(\mathrm{n}=1)$, pulmonary interstitial glycogenosis $3 \%(n=1)$, surfactant protein $C$ mutations $(S P-C) 5 \%(\mathrm{n}=2)$ and chronic bronchiolitis 3\% $(\mathrm{n}=$ 1). Median age at diagnosis was 35 weeks (range 1 week to 8 years), with 25 weeks the median time from first symptoms to diagnosis (range 1 week to 8 years). Areas of concern were (a) communication; care plans/treatment strategies were provided by a respiratory consultant in only 19 of 37 cases, (b) written information: $>50 \%$ families could not recall receiving any written information on ILD or their child's specific disease after diagnosis or information on their child's prognosis, (c) psychological support; $91 \%$ of respondents reported significant/moderate anxiety, however psychological services were reported as offered to only 7 of 37 families, (d) feeding issues; reported by $77 \%$ of families (which is not a feature of ILD described in the literature) and these persisted in 35\%, mostly long-term gastrostomy dependency and oral aversion. Qualitative responses included requests for better written communication between hospitals and training for smaller hospitals, and improved specialist nurse support of children with ILD.

Conclusion These data provide a broader understanding of parent experiences and perspectives, which should be important now for professionals looking after children with ILD as well as for those planning of future services.

\section{P99 COMPARISON OF MULTIPLE BREATH WASHOUT USING A COMMERCIAL DEVICE AND A MASS SPECTROMETER IN SCHOOL AGE CHILDREN WITH CYSTIC FIBROSIS}

${ }^{1}$ JA Duncan, ${ }^{1}$ E Raywood, ${ }^{2}$ A Bush, ${ }^{3}$ J Stocks, ${ }^{1}$ P Aurora. ${ }^{1}$ UCL Institute of Chi Ld Health and Great Ormond Street Hospital for Children, London, UK; ${ }^{2}$ Imperial College and Royal Brompton and Harefield Hospital NHS Foundation Trust, London, UK; ${ }^{3}$ UCL Institute of Child Health, London, UK

\subsection{6/thoraxjnl-2014-206260.240}

Background Lung clearance index (LCI) measured by multiple breath washout $(\mathrm{MBW})$ is a sensitive indicator of early lung disease in Cystic Fibrosis (CF). ${ }^{1} \mathrm{MBW}$ using sulphur hexafluoride $\left(\mathrm{SF}_{6}\right)$ and mass spectrometry (MS) is currently the gold standard, but equipment is limited to a few centres. Although commercial devices based on $\mathrm{SF}_{6}$ have been developed, use of $\mathrm{SF}_{6}$ is expensive and restricted in some countries. Commercial devices using nitrogen $\left(\mathrm{N}_{2}\right)$, which is cheaper and widely available, have been developed recently to increase accessibility of this test in research and clinical practice but have yet to be validated in children. The aim of this study was to compare values of LCI and Functional Residual Capacity (FRC) in children using the $\mathrm{N}_{2}-\mathrm{MBW}$ EasyOne Pro ${ }^{\circledR}$ LAB system (ndd Medical Technologies) and the MS (AMIS 2000, Innovision ApS).

Methods School-age children with CF and healthy controls completed MBW in triplicate on both the EasyOne Pro® and MS in random order on the same occasion. Within-subject agreement between devices for LCI and FRC was assessed by Bland-Altman analysis.

Results Of the 50 children recruited, all completed testing using MS, while 5 failed quality control on the EasyOne Pro® LAB. Paired results from both devices were obtained in 26 children with CF (mean age [range]) (13.3y[7.8y-17.4y]) and 19 controls

\section{LCI COMPARISON}

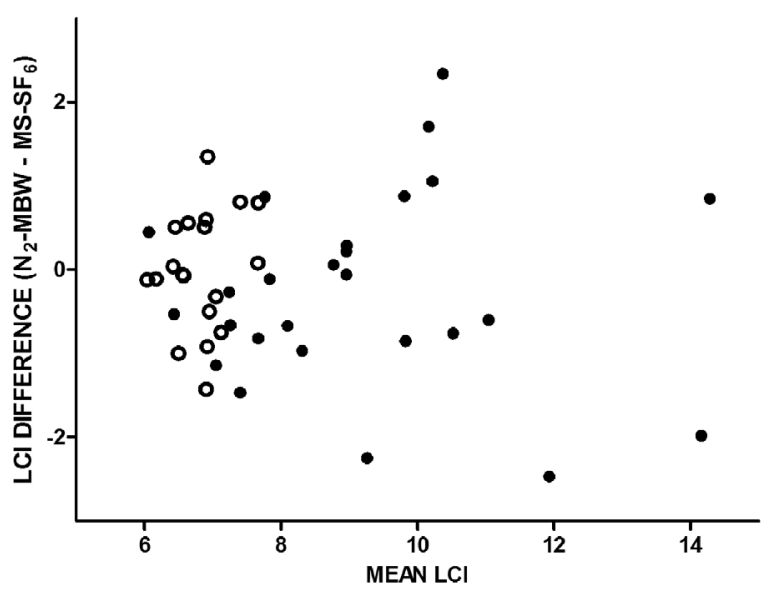

\section{FRC COMPARISON}

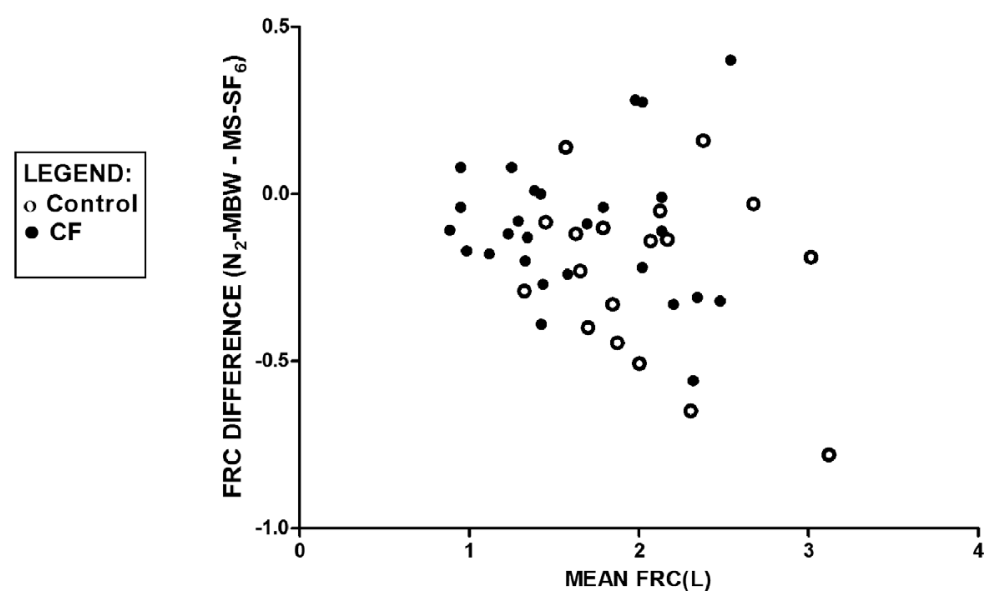

Abstract P99 Figure 1 Bland-Altman comparison of LCl and FRC between MBW devices. Limits of agreement not shown as variability of the differences are proportional to mean values 
(14.8y [12.5y-16.7y]). LCI was significantly higher in those with CF when using both devices (mean difference[95\% CI], CF-controls): $2.47[1.4 ; 3.5]$ for the $\mathrm{MS}_{-} \mathrm{SF}_{6}$ and 2.20[1.2-3.2] for $\mathrm{N}_{2^{-}}$ MBW.

There were no significant group differences between devices for either LCI (mean difference[95\% CI]) $-0.14[-0.45 ; 0.16]$ or FRC $-0.15 \mathrm{~L}[-0.2 ;-0.08]$. Within-subject variability was proportional to mean values (see Figure) and ranged from $0.4-15.7 \%$ for LCI and $0.0-19.6 \%$ for FRC.

Conclusion Despite some previous reports that $\mathrm{N}_{2}$-washout results in higher LCI values than $\mathrm{MS}_{-} \mathrm{SF}_{6}$ washout, on average, we found similar values in both healthy school-age children and those with CF. Further work is required to examine causes of withinsubject variability and assess validity and sensitivity over a wider age range, including preschool children, before commercial $\mathrm{N}_{2}$-MBW devices can be confidently used in multi-centre trials.

\section{REFERENCE}

1 Aurora et al. Am J Respir Crit Care Med. 2011:183:752-8

\section{P100 THE FEASIBILITY OF USING COMMERCIAL MULTIPLE BREATH NITROGEN WASHOUT DEVICES IN SCHOOL- AGED CHILDREN}

'E Raywood, 'I Duncan, 'S Legg, ${ }^{2} \mathrm{P}$ Aurora, '1 Stocks. 'Instititue of Child Health, Univeristy College London, London, UK; ${ }^{2}$ Great Ormond Street Hospital and NHS Foundation Trust, London, UK

\subsection{6/thoraxjnl-2014-206260.241}

Background Multiple breath inert-gas washout (MBW) using sulphur hexafluoride $\left(\mathrm{SF}_{6}\right)$ measured by mass spectrometry (MS), is sensitive to early lung disease in children with Cystic Fibrosis $(\mathrm{CF})^{1}$ but is not widely available. To increase the accessibility of $\mathrm{MBW}$, commercial devices have been adapted using nitrogenwashout $\left(\mathrm{N}_{2}-\mathrm{MBW}\right)$. Our aim was to assess the feasibility of two commercial $\mathrm{N}_{2}-\mathrm{MBW}$ devices as supplied by the manufacturers compared to a custom-built MS system in school-aged children.

Methods Patients with $\mathrm{CF}$ and controls performed MBW on three devices; the Exhalyzer ${ }^{\circledR} \mathrm{D}$ (ECO MEDICS AG); the EasyOne Pro ${ }^{\circledR} \mathrm{LAB}$ (ndd Medizintechnik AG) and the MS system (AMIS 2000, Innovision ApS) on the same test occasion (order randomised). Attempts were made to obtain 3 technically acceptable runs/device (maximum 8 attempts on each).

During testing children watched a DVD and were encouraged to breathe normally. Data were analysed using the 'clinical application' setting for both commercial devices, and customised software for the MS. Quality control was in accordance with the ATS/ERS consensus statement ${ }^{1}$ and manufacturers' guidelines.

Results 14 control (mean[range]age: 15.0[12.5-16.7]yrs) and 18 children with CF (13.5[7.8-17.4]yrs) were assessed. The median (range) number of runs attempted were: MS 3(3-8), Exhalyzer ${ }^{\circledR}$ D 4(3-6), EasyOne Pro ${ }^{\circledR} \mathrm{LAB}$ 4(3-8). Average calibration time was shorter for EasyOne Pro ${ }^{\circledR} \mathrm{LAB}(5 \mathrm{~min})$ than either MS (11 mins) or Exhalyzer ${ }^{\circledR} \mathrm{D}$ (12 min). Total test duration was similar between devices and dependent on disease severity.

3 acceptable MBW runs were achieved in all children using the MS, $75 \%$ with the EasyOne Pro ${ }^{\circledR} \mathrm{LAB}$, and $47 \%$ on the Exhalyzer ${ }^{\circledR} \mathrm{D}$ system (see Table). Reasons for failure with Exhalyzer ${ }^{\circledR} \mathrm{D}$ were usually due to technical/equipment problems, whereas for the EasyOne Pro ${ }^{\circledR} \mathrm{LAB}$ these were generally associated with marked changes of breathing pattern at commencement of washout, leading to exclusion of one or more runs.

Discussion Despite use in an experienced MBW centre, our initial attempts to implement commercial MBW devices according
Abstract P100 Table 1 Number (n) of technically satisfactory runs according to MBW device

\begin{tabular}{llll}
\hline & MS & EasyOne Pro Lab & Exhalyzer D \\
\hline $\mathrm{n}=3$ & 32 & 24 & 15 \\
$\mathrm{n}=2$ & 0 & 7 & 1 \\
$\mathrm{n}=1$ & 0 & 0 & 1 \\
None acceptable & 0 & 1 & 15 \\
\hline
\end{tabular}

to manufacturers' guidelines resulted in a relatively low success rate in schoolchildren when compared to MS. Subsequent feedback to manufacturers has led to further adaptations which should improve feasibility in future, although this has yet to be assessed in very young children.

\section{REFERENCE}

1 Robinson et al. Eur Resp J 2013

\section{P101 EFFECTS OF USING A MASK VS. MOUTHPIECE ON THE MULTIPLE BREATH INERT GAS WASHOUT TECHNIQUE}

${ }^{1} \mathrm{~S}$ Lum, ${ }^{1} \mathrm{~J}$ Stocks, ${ }^{2} \mathrm{~W}$ Kozlowska, ${ }^{3} \mathrm{P}$ Aurora. ' UCL, Institute of Chi Ld Health, London, UK; ${ }^{2}$ Kings College Hospital NHS Foundation Trust, London, UK; ${ }^{3}$ Great Ormond Street Hospital for Children NHS Foundation Trust, London, UK

\subsection{6/thoraxjnl-2014-206260.242}

Assessment of ventilation inhomogeneity using the multiple breath washout (MBW) technique has been shown to be more sensitive than spirometry in detecting early cystic fibrosis lung disease throughout childhood. The current "gold standard" interface for school age children and adults is a mouthpiece. Although masks are better tolerated by infants and younger children, their use increases equipment deadspace-which could influence measured values and hence interpretation of results. The aim of this study was to examine the effect of using a mask vs mouthpiece on values of functional residual capacity (FRC) and the lung clearance index (LCI) derived from MBW.

Method Comparisons were performed in healthy adults. The study design incorporated repeated measures as well as interface comparison. The mask was selected to mimic measurement conditions in infants, the deadspace of $85 \mathrm{~mL}$ being approximately $1-2 \mathrm{ml} / \mathrm{kg}$ in adults. Mouthpiece (MP) deadspace was $\sim 5 \mathrm{ml}$. Subjects were randomly allocated to group A (Mask-Mouthpiece-Mouthpiece) or group B (Mouthpiece-Mouthpiece-Mask) protocols. Each subject performed a total of 9 MBW runs, in 3 sets, each consisting of 3 runs, with a 5 -minute break between each set. MBW was performed using a mass spectrometer as described previously (Aurora 2005 AJRCCM). Paired t-tests with 95\% limits of agreement were used to establish repeatability (MP1 vs. MP2) and any differences between Mask vs. Mouthpiece. This study was approved by the local research ethics committee and written consent obtained from subjects.

Results Technically satisfactory comparative data were obtained on 15 occasions in 14 adults (36\% males; age: $22-56$ years). Respiratory rate and tidal volume were similar using either approach. Repeatability: Both FRC and LCI were repeatable using the mouthpiece [(Mean $(95 \%$ CI) diff: FRC: 0.012L $(-0.05 ; 0.07)$; LCI: $-0.1(-0.3 ; 0.1)]$; Figure $1 \mathrm{~A}$ and B. Mask vs. Mouthpiece: FRC and LCI were both significantly higher when assessments were made using a mask compared with a mouthpiece: FRC: 0.101L (0; 0.202); LCI: 0.4 (0.2;0.7); Figure 1C and D.

Conclusion The increase in LCI when using a facemask exceeded normal within test variability in adults and could 